(C) 2020, The Authors. Published by Elsevier Inc. and Fass Inc. on behalf of the American Dairy Science Association ${ }^{\circledR}$. This is an open access article under the CC BY-NC-ND license (http://creativecommons.org/licenses/by-nc-nd/4.0/).

\title{
Growth and survival characteristics of Paucilactobacillus wasatchensis WDCO4
}

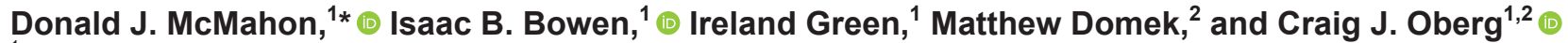 \\ ${ }^{1}$ Western Dairy Center, Department of Nutrition, Dietetics, and Food Sciences, Utah State University, Logan 84322-8700 \\ ${ }^{2}$ Microbiology Department, Weber State University, Ogden, UT 84408-2506
}

\begin{abstract}
Understanding characteristics that permit survival and growth of Paucilactobacillus wasatchensis as part of the nonstarter microbiota of cheese is important for minimizing unwanted gas formation in cheese that can cause downgrading because of slits and cracks. The ability of Plb. wasatchensis WDC04 to survive pasteurization was studied by inoculating raw milk with $10^{8} \mathrm{cfu} /$ $\mathrm{mL}$ and measuring survival after processing through a high-temperature, short-time pasteurizer. Extent and rate of growth of Plb. wasatchensis WDC04 as a function of $\mathrm{pH}$, salt concentration, and presence of various organic acids were studied using 48-well microplates in an automated spectrophotometer measuring optical density at $600 \mathrm{~nm}$. Better growth in the $1-\mathrm{mL}$ wells was obtained when a micro-anaerobic environment (similar to that which occurs in cheese) was created by enzymically removing the oxygen. Faster growth occurred around neutral $\mathrm{pH}(\mathrm{pH} 6$ to 8$)$ than at $\mathrm{pH} 5$ (cheese $\mathrm{pH}$ ), whereas only marginal growth occurred at $\mathrm{pH}$ 4. Adding sodium chloride retarded growth of $\mathrm{Plb}$. wasatchensis WDC04, but slow growth occurred even at salt concentrations up to $6 \%$. At salt-in-moisture (S/M) concentrations found in cheese, the rate of growth at $3.5 \% \mathrm{~S} / \mathrm{M}>4.5 \% \mathrm{~S} / \mathrm{M}>5.5 \% \mathrm{~S} / \mathrm{M}$. Thus, low salt level in cheese is a risk factor for Plb. wasatchensis growth during cheese storage and unwanted slits and cracks. Some of the organic acids tested (propionic, formic, and citric) tended to suppress growth of Plb. wasatchensis WDC04 more than would be expected from their effect on $\mathrm{pH}$. No survival of Plb. wasatchensis WDC04 after pasteurization was observed with the reduction in numbers being $8 \operatorname{logs}$ or more. Even subpasteurization heating at $69^{\circ} \mathrm{C}$ for $15 \mathrm{~s}$ was sufficient to inactivate $P l b$. wasatchensis WDC04, so its presence as part of the nonstarter microbiota of cheese should be considered as a postpasteurization environmental contamination.
\end{abstract}

Received March 26, 2020.

Accepted May 19, 2020.

*Corresponding author: Donald.McMahon@usu.edu
Key words: pasteurization, lactobacilli, nonstarter, salt

\section{INTRODUCTION}

Quality issues in cheese arising from the presence of obligatory heterofermentative $(\mathbf{O H F})$ lactobacilli are problematic and a source of unwanted gas production leading to splits and downgrading of cheese. Cheese with slits, splits, or cracks is unsuitable for conversion into sliced cheese because modern slicing machines operate at up to 20 slices per second. One such OHF bacteria was isolated from a puffy bag of cheese in 2012 and given the name Lactobacillus wasatchensis (pronounced wa.satch.en'sis; Oberg et al., 2016) and has now been reclassified as a lactobacilli in the Paucilactobacillus (pronounced pow-kee.lac.to.bacil'lus) genera (Zheng et al., 2020). The species was initially presumptively designated as Lactobacillus wasatchii (Ortakci et al., 2015a). All of the previously designated members of the genus Lactobacillus can still be referred to as lactobacilli even though they have different genera names because they are still part of the Lactobacillaceae family (Zheng et al., 2020).

The Paucilactobacillus genus describes a group of lactobacilli that ferment few carbohydrates, and hence, their name is derived from the Latin paucus meaning "few." They are gram-positive, rod-shaped, catalase negative, heterofermentative, and aerotolerant with growth observed between 20 and $37^{\circ} \mathrm{C}$. Strains in this genus were predominantly isolated from fermented plant material including silage, pickles, and fruit mashes, whereas Plb. wasatchensis was first isolated from cheese in Utah (United States) and named after the Wasatch mountains. These are lactobacilli that have adapted to hexose-depleted habitats as indicated by the lack of mannitol dehydrogenase in many strains of this genus. Among the heterofermentative lactobacilli, this property is shared only with Secundilactobacillus that is isolated from related habitats and found as secondary bacteria in fermentation processes. Paucilactobacillus species preferentially metabolize pentoses, and many 
strains, such as Plb. wasatchensis, do not ferment disaccharides (Zheng et al., 2020).

The type species for the Paucilactobacillus genus is Plb. vaccinostercus (Zheng et al., 2020), which has been isolated from cow dung, fermented tea leaves, and fermented cereals. Other species include Plb. hokkaidonensis (isolated from grass silage), Plb. kaifaensis (isolated from fermented Chinese cabbage), Plb. nenjiangensis (isolated from pickles), Plb. oligofermentans (isolated from marinated poultry meat at the end of its shelf life, and from fermented olives), Plb. suebicus (isolated from fermented cherry mashes, cider, and silage), and $P l b$. wasatchensis (isolated from cheese).

Many of the lactobacilli that have been associated with dairy foods also have reclassified genus names. The homofermentative Lactobacillus delbrueckii remaining as the type species for the Lactobacillus genus with Lactobacillus delbrueckii ssp. bulgaricus, Lactobacillus helveticus, Lactobacillus acidophilus, and Lactobacillus kefiranofaciens being its most common dairy members. The homofermentative casei group of lactobacilli is now designated as Lacticaseibacillus with Lacticaseibacillus casei as the type strain and also includes Lacticaseibacillus paracasei and Lacticaseibacillus rhamnosus.

The most common nonstarter lactic acid bacteria (NSLAB) found in cheese in North America is now designated as Latilactobacillus curvatus and is part of a homofermentative genus whose members have a broad range of habitats (latus means wide), and the strains in the species lead a free-living lifestyle and are mesophilic (many strains are also psychrotrophic). Latilactobacillus sakei is the type species. Another group of homofermentative lactobacilli is the Ligilactobacillus genus that have a host-associated lifestyle (from ligare meaning to unite). The type species is Ligilactobacillus salivarius and several of the species commonly occur in fermented foods and are used commercially as starter cultures or probiotic cultures. This genus also includes Ligilactobacillus ruminis that is found in the rumen of cows as well as in the gut of humans (and other mammalian species).

The homofermentative plantarum lactobacilli group is now designated as the Lactiplantibacillus genus based on their being found in both milk and plant-based fermented foods. Lactiplantibacillus plantarum is the type species. A group of lactobacilli with spoilage potential (loigos meaning destruction, ruin, or havoc) form the Loigolactobacillus genus with Loigolactobacillus coryniformis being the type species. Loigolactobacillus bifermentans has been isolated from Dutch-style cheese where it can cause small cracks due to fermentation of lactic acid into acetic acid, ethanol, traces of propionic acid, carbon dioxide, and hydrogen. Another member of this genus is Loigolactobacillus rennini that was isolated from rennet and associated with cheese spoilage.

There are multiple genera of heterofermentative lactobacilli in addition to Paucilactobacillus. A group of lactobacilli that can produce exopolysaccharides from sucrose and produce a slimy texture to foods (limosus means slimy) make up the genus Limosilactobacillus. These bacterial species generally form stable associations with species in the Lactobacillus genus. The type species is Limosilactobacillus fermentum and also included in the group is Limosilactobacillus reuteri. The Secundilactobacillus genus is another group of bacteria that, like the Paucilactobacillus, have been isolated from hexose-depleted habitats such as silage, beer, liquor mashes, and apple cider. They share a common trait with the Paucilactobacillus bacteria of not being able to reduce fructose to mannitol and are found as spoilage organisms in fermented foods after the primary fermenting bacteria has depleted the substrate of hexoses. A few species have also been found in silage. The type species is Secundilactobacillus malefermentans.

A group of lactobacilli known for their gas-producing ability is the Levilactobacillus genus (levare means to lift up or release) that have leavening ability as shown in their use in sourdough bread. The type species is Levilactobacillus brevis, which has also been associated with unwanted gas production in cheese.

Culumber et al. (2017) found that the incidence is not localized to just the type strain (WDC04) isolated in Utah, but extended across the United States with various strains being isolated from cheeses made in the western and midwestern states, suggesting that $P l b$. wasatchensis is probably ubiquitous in cheese. Further isolates of species closely related to Plb. wasatchensis WDC04 have been obtained from cheese produced in the eastern United States and a cheese produced in Ireland (unpublished data). Isolation of Plb. wasatchensis and other OHF NSLAB from cheese is hampered because of their slower growth rate than more prevalent NSLAB. In the case of Plb. wasatchensis, its optimum growth temperature of $\sim 23^{\circ} \mathrm{C}$ results in very little growth at the $37^{\circ} \mathrm{C}$ incubation temperature normally used to enumerate NSLAB, such as Ltlb. curvatus or Lcb. casei, in cheese.

Paucilactobacillus wasatchensis preferentially metabolizes 5-carbon sugars, such as ribose, using the pentose phosphate pathway (Ortakci et al., 2015a). It can slowly grow by metabolizing 6-carbon sugars such as galactose using the Leloir pathway. When this occurs, a carbon is cleaved off that eventually goes to produce $\mathrm{CO}_{2}$, which causes gassiness and blowing packages in aging cheese (Ortakci et al., 2015a). Some of the risk factors recently identified for having unwanted 
gas production and formation of splits and cracks during storage of Cheddar cheese are (1) the cheese initially having high numbers of NSLAB that include Plb. wasatchensis or other OHF lactobacilli; (2) high levels of residual galactose in the cheese that can come from use of Streptococcus thermophilus as a component of the starter culture; (3) use of elevated temperature during cheese storage; and possibly (4) high numbers of starter culture in the cheese curd followed by cell lysis that makes ribose and other nutrients available to NSLAB in the cheese (Ortakci et al., 2015a,b,c; Oberg et al., 2016; Culumber et al., 2017).

To minimize the presence of Plb. wasatchensis in cheese it is necessary to understand its entry point into the cheese factory, its presence in cheese milk, and its growth characteristics and survival. The most likely origin of Plb. wasatchensis on the dairy farm is silage as closely related OHF lactobacilli have been isolated from fermented plant material (Oberg et al., 2016). This organism could then enter the cheese factory in the raw milk, and a previous study (Ortakci et al., 2015a) suggested that $0.003 \%$ of the bacterial cells of Plb. wasatchensis WDC04 could survive a pasteurization treatment of $15 \mathrm{~s}$ at $72^{\circ} \mathrm{C}$. Such survival would allow entry of Plb. wasatchensis into the cheese processing facility where it could become part of biofilms that then seed NSLAB into milk, whey, and cheese curd. However, in that same study no viable Plb. wasatchensis WDC04 was recovered with a pasteurization heat treatment of $63^{\circ} \mathrm{C}$ for $30 \mathrm{~min}$.

Because one strategy for preventing unwanted gas production in cheese is to keep the numbers of $P l b$. wasatchensis in the cheese low, it is important to know its growth characteristics and carbohydrate sources that can promote its growth in cheese. Ortakci et al. (2015a) and Oberg et al. (2016) have demonstrated the rapid growth of Plb. wasatchensis WDC04 on ribose with slower growth on galactose. These 2 sugars are present in cheese from lysis of starter (or adjunct) culture cells and incomplete fermentation of lactose by the starter cultures, respectively. Ribose makes up about $40 \%$ of RNA in bacterial cells (Zeibich et al., 2019). Two other materials that could be scavenged and utilized from lysed cells are $\mathrm{N}$-acetylglucosamine (NAG) and $N$-acetylmuramic acid (NAM). These are components and building blocks for the peptidoglycan of bacterial cell (glucosamine and NAG are among the most abundant sugars on the planet; Moye et al., 2014) and can provide biofilm bacteria with carbon, nitrogen, and energy.

Our aim was to further characterize the potential carbohydrate sources that would support growth of Plb. wasatchensis WDC04 in cheese, to confirm its salt tolerance and whether it can survive HTST pasteurization. We were also interested in whether the presence of various organic acids in cheese influence Plb. wasatchensis WDC04 growth.

\section{MATERIALS AND METHODS}

\section{Materials}

Chemicals and Media. Lactobacilli de Man, Rogosa, and Sharpe (MRS) broth was from Hardy Diagnostics (Santa Maria, CA) and Becton Dickinson and Co. (Sparks, MD); Oxyrase for Broth, sodium chloride, glucose, fructose, $0.2-\mu \mathrm{m}$ membrane filters (for filter sterilization), sodium citrate, potassium phosphate, acetate-EDTA, ethanol, citric acid, and dipotassium phosphate were from Fisher Scientific Inc. (Fair Lawn, NJ). Tris-HCl was from Fisher Bioreagents (Pittsburgh, PA); bacteriological agar, proteose peptone no. 3, beef extract, and yeast extract were from Becton Dickinson and Co. Ribose and GasPak EZ pouches were from VWR (Solon, OH); and Tween-80, SDS, NAM, and NAG were from Sigma-Aldrich Inc. (St. Louis, MO). Falcon 48 transparent micro-well plates with lids were from Corning Inc. (Corning, NY). Sodium acetate and ammonium citrate were purchased from Mallinckrodt Baker Inc. (Paris, KY); formic acid was from Mallinckrodt Pharmaceuticals (St. Louis, MO); magnesium sulfate was from Alfa Aesar Inc. (Heysham, UK); manganese sulfate, galactose, and lactose came from J.T. Baker Chemical Co. (Phillipsburg, NJ); lactic, propionic, and acetic acids were from Avantor Performance Materials LLC (Center Valley, PA).

Raw whole milk was from the Caine Dairy Teaching and Research Center (Utah State University, Wellsville) and pasteurized $\left(63^{\circ} \mathrm{C}\right.$ for $\left.30 \mathrm{~min}\right)$ by the Aggie Creamery (Utah State University). Ultra-high-temperature milk was obtained from Gossner Foods (Logan, UT). Whirl-Pak filtered stomacher bags were purchased from Nasco (Fort Atkinson, WI).

Bacterial Cultures. Working cultures of Plb. wasatchensis WDC04 were obtained from frozen stocks (Weber State University, Ogden, UT) and grown in MRS broth supplemented with 1.0 to $1.5 \%$ ribose (MRS-R) at $25^{\circ} \mathrm{C}$. Every 2 to $3 \mathrm{~d}$, fresh tubes of MRS-R were inoculated with the bacterium to keep the bacterium in logarithmic growth. Frozen cultures were stored at $-80^{\circ} \mathrm{C}$ in $1-\mathrm{mL}$ aliquots supplemented with $20 \%$ sterile glycerine. Agar plates were made from MRS-R broth with the addition of $1.5 \%$ agar. Spread plates were stored at $\sim 25^{\circ} \mathrm{C}$ in anaerobic incubation jars with GasPak EZ. Test batches of Plb. wasatchensis WDC04 were prepared by adding $4 \mathrm{~mL}$ of working cul- 
ture into $9 \mathrm{~mL}$ of MRS-R and incubated for $2 \mathrm{~h}$, then adjusted to an optical density (OD) at $600 \mathrm{~nm}$ of 0.90 for $\mathrm{pH}$, salt, and carbohydrate studies, and 0.25 for studying inhibitory effects of organic acids.

Carbohydrate-Restricted MRS. A stock solution of carbohydrate-restricted MRS (CR-MRS) broth was prepared by adding the ingredients listed in Table 1 to deionized water. To simulate potential for growth in a cheese environment, the solution was then adjusted to $\mathrm{pH} 5.2$ with $\mathrm{HCl}$ and $4.5 \%$ salt added. Twenty percent (wt/vol) stock solutions of each carbohydrate (glucose, lactose, fructose, galactose, ribose, NAG, and NAM were filter sterilized $(0.2-\mu \mathrm{m}$ pore size $)$ and then $7.5-\mathrm{mL}$ aliquots were added to $92.5 \mathrm{~mL}$ of CR-MRS to produce individual broth solutions containing $1.5 \%$ (wt/vol) of a specified carbohydrate.

\section{Thermotolerance}

Thermotolerance of Plb. wasatchensis was studied using a HTST pasteurizing heat exchanger (model SP15, APV Crepaco, Tonawanda, NY) in the Gary Haight Richardson Dairy Products Laboratory (Utah State University) operating at $20 \mathrm{~L} / \mathrm{min}$ with regeneration, heating, and cooling sections. It was previously determined that a $30-\mathrm{L}$ aliquot of milk begins to exit the pasteurizer 2 min after its addition to the pasteurizer's constant level tank. Undiluted heat-processed milk could then be obtained between 3 min and 3 min $40 \mathrm{~s}$ (Supplemental Figure S1; https://doi.org/10.3168/jds .2020-18597).

Four 3-L bottles of sterile MRS broth containing $2 \%$ ribose (wt/vol) were inoculated with $1 \%$ (vol/vol) Plb. wasatchensis culture and incubated for $3 \mathrm{~d}$ at $22^{\circ} \mathrm{C}$. Then, it was transferred to $250-\mathrm{mL}$ bottles and centrifuged at $9,150 \times g$ for $10 \mathrm{~min}$ at $22^{\circ} \mathrm{C}$. The pellets from 8 tubes were collected and resuspended in UHT milk and then added to $30-\mathrm{L}$ cold pasteurized milk and held for $1 \mathrm{~h}$ to allow Plb. wasatchensis bacteria to acclimatize before the milk was heat processed. One 30-L batch of inoculated milk was heat processed for $15 \mathrm{~s}$ at each of the following temperatures: $69,72,74$, and $76^{\circ} \mathrm{C}$.

The pasteurizer was run with cold water until steadystate conditions were reached, then the constant level tank was allowed to drain, and then a $30-\mathrm{L}$ batch of cold milk was added to the system, followed by cold water when the milk had drained. A sample of unprocessed milk was retained, and triplicate samples of cooled heat-processed milk were collected as the milk exited the heat exchanger 180, 200, and $220 \mathrm{~s}$ after the milk was added to the constant level tank. Dilution series for the milk was performed and samples were plated on MRS-R agar and grown anaerobically at $25^{\circ} \mathrm{C}$ in jars containing GasPak EZ pouches. Colony counts
Table 1. Carbohydrate-restricted Lactobacillus de Man, Rogosa, and Sharpe (MRS) broth based on de Man et al. (1960)

\begin{tabular}{lc}
\hline Material $^{1}$ & Quantity $(\mathrm{g} / \mathrm{L})$ \\
\hline Proteose peptone no. 3 & 10.0 \\
Beef extract & 10.0 \\
Yeast extract & 5.0 \\
Sodium acetate & 5.0 \\
Ammonium citrate & 2.0 \\
Dipotassium phosphate & 2.0 \\
Tween-80 & 1.0 \\
Magnesium sulfate & 0.1 \\
Manganese sulfate & 0.05
\end{tabular}

${ }^{1}$ Proteose peptone no. 3, beef extract, and yeast extract (Becton Dickinson and Co., Sparks, MD); sodium acetate and ammonium citrate (Mallinckrodt Baker Inc., Paris, KY); dipotassium phosphate (Fisher Scientific Inc., Fair Lawn, NJ); Tween-80 (Sigma-Aldrich Inc., St. Louis, MO); magnesium sulfate (Alfa Aesar Inc., Heysham, UK); manganese sulfate (J.T. Baker Chemical Co., Phillipsburg, NJ).

were performed after 2, 5, and $10 \mathrm{~d}$ and the percentage survival of Plb. wasatchensis was calculated.

\section{Growth Studies}

Growth of Plb. wasatchensis WDC04 was studied utilizing an Infinite 200 Pro spectrophotometer (Tecan Production Corp., Chapel Hill, NC) using 48-well plates with lids. For control samples (uninoculated blank), $980 \mu \mathrm{L}$ of the appropriate broth was added into a well. For test samples, $930 \mu \mathrm{L}$ of broth was added followed by $50 \mu \mathrm{L}$ of Plb. wasatchensis broth. To help establish anaerobic-like conditions, $20 \mu \mathrm{L}$ of Oxyrase solution was added to reduce oxygen levels in the medium (or 20 $\mu \mathrm{L}$ of sterile deionized water as a comparison). Samples were inoculated in triplicate, along with triplicate uninoculated wells. A lid was placed on the plate, which was then inserted in the spectrophotometer.

The orbital plate shaking was set at $2 \mathrm{~s}$ with an amplitude of $3 \mathrm{~mm}$ and a frequency of $218 \mathrm{rpm}$ with a settle time of $5 \mathrm{~s}$. Every $60 \mathrm{~min}$ during $48 \mathrm{~h}$ of incubation, OD was measured using 25 measurements per reading, 4 readings per well in a $2 \times 2$ pattern at $2.7 \mathrm{~mm}$ from the edge of the well. A 3-h running average was calculated at each time point for each well to smooth the data. Optical density at $4 \mathrm{~h}$ was considered as the starting level and subsequent average change in OD during incubation over $48 \mathrm{~h}$ was determined after correcting for the average change in OD of the control uninoculated wells. The difference in absorbance for each 2 -h period was calculated and the largest value was designated as maximum specific growth rate $\left(\boldsymbol{\mu}_{\max }\right)$ and expressed as $\mathrm{OD} / \mathrm{h}$.

Effect of salt concentration and $\mathrm{pH}$ was studied using MRS-R broth containing up to $6 \%$ (wt/vol) sodium chloride and adjusted to various $\mathrm{pH}$ levels. For carbohydrate utilization, CR-MRS containing $1.5 \%$ (wt/vol) 
Table 2. Concentrations of organic acids found in aged Cheddar cheese (McMahon et al., 2014)

\begin{tabular}{lccc}
\hline & \multicolumn{3}{c}{ Concentration $(\mathrm{mM})$} \\
\cline { 2 - 4 } Acid & Low & Mid & High \\
\hline Lactic & 450 & 505 & 560 \\
Formic & 26 & 63 & 100 \\
Propionic & 6 & 38 & 70 \\
Citric & 12 & 13.5 & 15 \\
Acetic & 2.5 & 9.8 & 17 \\
\hline
\end{tabular}

of an individual carbohydrate was used. For organic acids (lactic, formic, propionic, citric, and acetic), 10-fold concentration solutions were prepared at low, mid, and high concentrations (Table 2) based on their measured levels in aged Cheddar cheese (McMahon et al., 2014). In place of some of the MRS-R broth, $100 \mu \mathrm{L}$ of the organic acid solution was added using a $0.2-\mu \mathrm{m}$ sterile filter.

\section{RESULTS AND DISCUSSION}

\section{Pasteurization}

No viable Plb. wasatchensis were recovered from milk pasteurized at 72,74 , or $76^{\circ} \mathrm{C}$ with a 15 -s hold time, or from milk that was subpasteurization heat treated at $69^{\circ} \mathrm{C}$. No colonies were observed on any of the plates (including the $10^{-1}$ dilution plate) even when the plates were incubated for $10 \mathrm{~d}$ to allow for recovery of any sublethally injured cells. This represents a greater than $8 \mathrm{log}$ reduction of $\mathrm{Plb}$. wasatchensis when milk is heated in a commercial-style HTST pasteurizer. Our prior study (Ortakci et al., 2015a) had predicted a $4.5 \mathrm{log}$ reduction, and this difference suggests that the amount of heat exposure in the test-tube experiment was less than what occurs in an industrial setting. In the laboratory model, the Plb. wasatchensis cells were added to medium already heated to $72^{\circ} \mathrm{C}$ and then rapidly cooled after $15 \mathrm{~s}$. In contrast, in the HTST system the cells are exposed to a longer period of heating as the milk passes through the warming regeneration section of the heat exchanger, then are held at the set temperature for 15 $\mathrm{s}$, before being cooled down in the cooling section of the heat exchanger. This time discrepancy was less of an issue when using a $63^{\circ} \mathrm{C}$ for $30 \mathrm{~min}$ pasteurization treatment in which heating and cooling in a test tube also showed no survival after pasteurization in broth containing $\sim 6 \times 10^{6} \mathrm{cfu} / \mathrm{mL}$ of Plb. wasatchensis WDC04 (Ortakci et al., 2015a). Because Plb. wasatchensis does not survive pasteurization, its presence as part of the NSLAB microbiota of cheese appears to be through environmental contamination postpasteurization.

\section{Growth of Plb. wasatchensis Using 48-Well Plates}

Paucilactobacillus wasatchensis, like other NSLAB found in cheese, is a facultative anaerobic bacteria and, hence, will only grow when oxygen is absent or at very low levels. Because the surface area to volume ratio of $1 \mathrm{~mL}$ of liquid in the wells of 48 -well plates is relatively high compared with bottles and test tubes, the dissolved oxygen in the medium slows its growth. Using Oxyrase to create a micro-anaerobic environment by chemically removing oxygen increased both the rate and extent of growth of Plb. wasatchensis (Figure 1) under these experimental conditions. After $48 \mathrm{~h}$ of incubation, the OD increased from 1.2 to 1.5 when Oxyrase had been added to the medium. Adding Oxyrase also decreased the variation among replicate trials especially when the growth rate was slower (data not shown). After $48 \mathrm{~h}$ of incubation, standard error of means were as high as 0.075 when Oxyrase was not used and were only 0.02 to 0.03 with Oxyrase.

During the first few hours of incubation in the 48well plates, sometimes the OD increased or decreased, especially when additives such as the organic acids were added to the medium. There is only marginal growth of Plb. wasatchensis at the beginning of incubation (not enough to affect OD readings), so the OD at $4 \mathrm{~h}$ was considered as the baseline for comparing with later OD readings. Any changes in OD before $4 \mathrm{~h}$ were considered to be the test medium and added components coming to equilibrium.

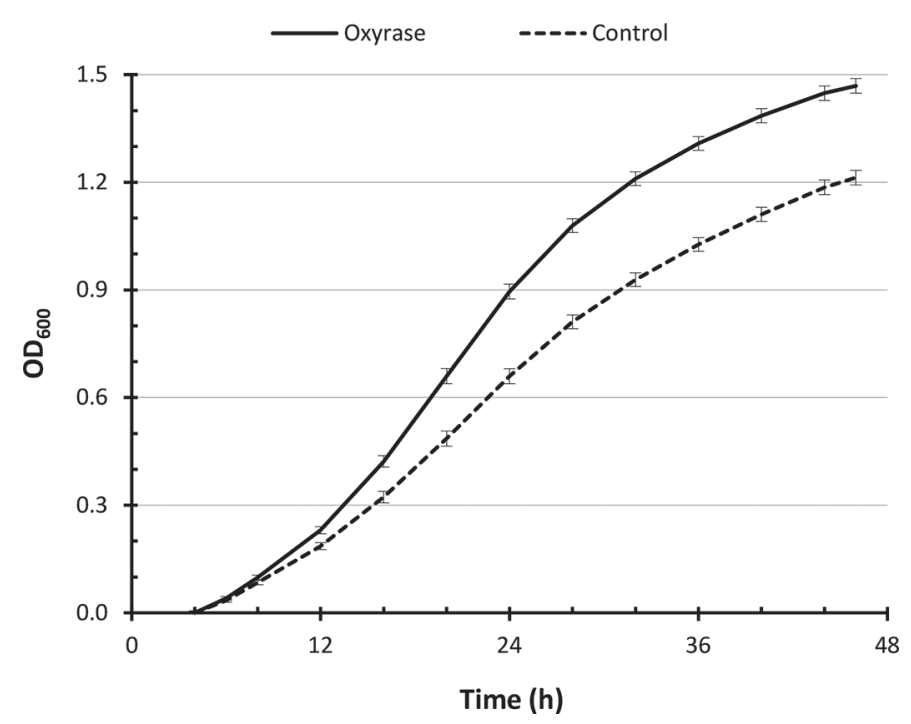

Figure 1. Growth of Paucilactobacillus wasatchensis at $25^{\circ} \mathrm{C}$ with (solid line) and without (dashed line) Oxyrase (Fisher Scientific Inc., Fair Lawn, NJ) added to de Man, Rogosa, and Sharpe (MRS)-ribose broth, $\mathrm{pH} 5.2$, in 48-well plates based on optical density measured at $600 \mathrm{~nm}\left(\mathrm{OD}_{600}\right)$, error bars $=\mathrm{SE}, \mathrm{n}=3$. 
$\mathrm{pH}$

Growth of Plb. wasatchensis was similar in the range of $\mathrm{pH} 6$ to $\mathrm{pH} 7$ with mean $\mu_{\max }=0.16 \mathrm{OD} / \mathrm{h}$. Lowering the $\mathrm{pH}$ to that typical of Cheddar cheese ( $\mathrm{pH} 5.2$ to 5.0) slowed down its growth with mean $\mu_{\max }$ dropping to 0.11 and $0.085 \mathrm{OD} / \mathrm{h}$, respectively (Figure 2). After $48 \mathrm{~h}$ of incubation at $25^{\circ} \mathrm{C}$, this slowing of growth was such that OD only reached 1.35 and 1.22 , respectively, compared with 1.67 at $\mathrm{pH} 6.0$. When the $\mathrm{pH}$ of the MRS-R broth was further lowered, there was acid inhibition of Plb. wasatchensis with only marginal growth occurring at $\mathrm{pH} 4$ (Figure 2). Because fermentation of ribose by $\mathrm{Plb}$. wasatchensis results in production of lactic acid and a lowering of $\mathrm{pH}$, it may be that when it is grown in MRS-R broth adjusted to $\mathrm{pH} 5.2$ or 5.0 some acid inhibition may occur during continued incubation. In this experiment, incubation was only conducted for $48 \mathrm{~h}$, and the stationary phase, which occurs when ribose is depleted (Ortakci et al., 2015a), had not been reached. It is possible that if the medium was more strongly buffered to prevent acid inhibition then the same final OD would be reached as when it is grown at neutral $\mathrm{pH}$ but takes a longer time.

When the medium was adjusted to $\mathrm{pH}$ 8.0, growth was slightly faster $\left(\mu_{\max }=0.17 \mathrm{OD} / \mathrm{h}\right)$ and to a greater extent (final OD $=1.77$ after $48 \mathrm{~h}$ ) compared with 1.67 at $\mathrm{pH} 7.0$ (Figure 3). This is probably a function of the $\mathrm{pH}$ of the medium remaining slightly higher during incubation. Increasing $\mathrm{pH}$ to 9.0 resulted in an extension of the lag phase in which no appreciable increase in OD was observed from $4 \mathrm{~h}$ to almost $24 \mathrm{~h}$. However, during the next $24 \mathrm{~h}$, the growth in Plb. wasatchensis was the fastest $\left(\mu_{\max }=0.18 \mathrm{OD} / \mathrm{h}\right)$ and it reached a similar OD level after $48 \mathrm{~h}$. At pH 9 the bacterial cells would be under alkaline stress and the longer lag time may reflect an induced change in cellular metabolism to maintain a neutral intracellular $\mathrm{pH}$. Also, during the initial slow growth of Plb. wasatchensis, enough lactic acid may have been produced to lower the extracellular $\mathrm{pH}$ to a level where normal growth could occur.

\section{Salt Tolerance}

When Plb. wasatchensis was grown in MRS-R at $\mathrm{pH}$ 6.5 , addition of $5.4 \%$ salt strongly inhibited growth such that OD after $46 \mathrm{~h}$ of incubation at $25^{\circ} \mathrm{C}$ was only about 0.18. In comparison, when no salt was added growth was rapid and OD reached a level of 1.85. Adding more salt further suppressed growth so that at $5.5 \%$ salt the OD only reached 0.16 and with $6.0 \%$ salt it only reached 0.07 . This is different than previously observed by Ortakci et al. (2015a) in which adding salt up to $5 \%$ slowed growth of Plb. wasatchensis WDC04 but

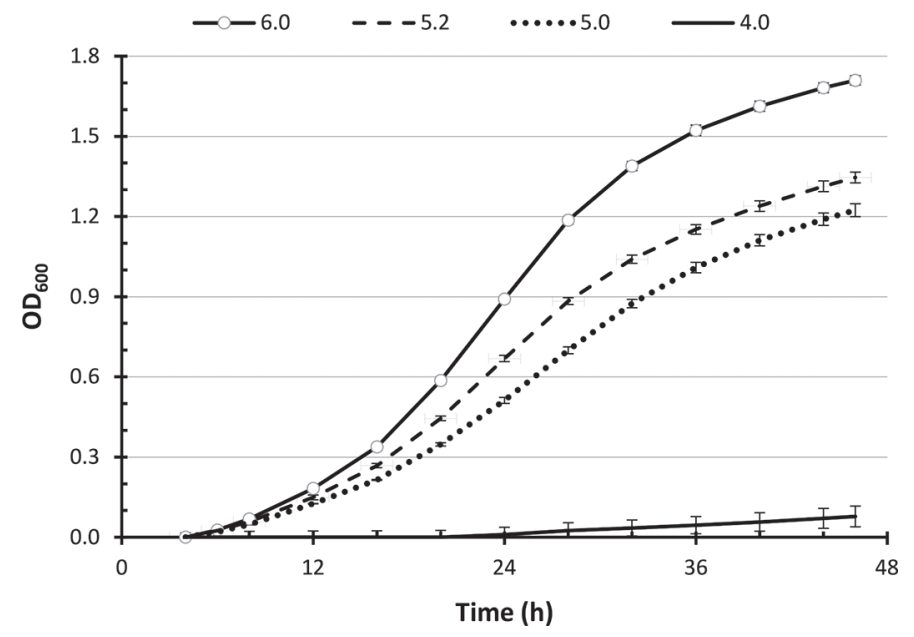

Figure 2. Growth of Paucilactobacillus wasatchensis at $25^{\circ} \mathrm{C}$ in de Man, Rogosa, and Sharpe (MRS)-ribose broth at $\mathrm{pH}$ 6.0, 5.2, 5.0, and 4.0 in 48 -well plates with optical density measured at $600 \mathrm{~nm}\left(\mathrm{OD}_{600}\right)$, error bars $=\mathrm{SE}, \mathrm{n}=3$.

all samples reached the same OD after $60 \mathrm{~h}$ of incubation. This may reflect differences in the environment within the medium when using test tubes containing $10 \mathrm{~mL}$ of medium compared with $1 \mathrm{~mL}$ in microwells. It may be that even with the addition of Oxyrase, the microwells are still more hostile for supporting growth of Plb. wasatchensis because of trace amounts of dissolved oxygen remaining.

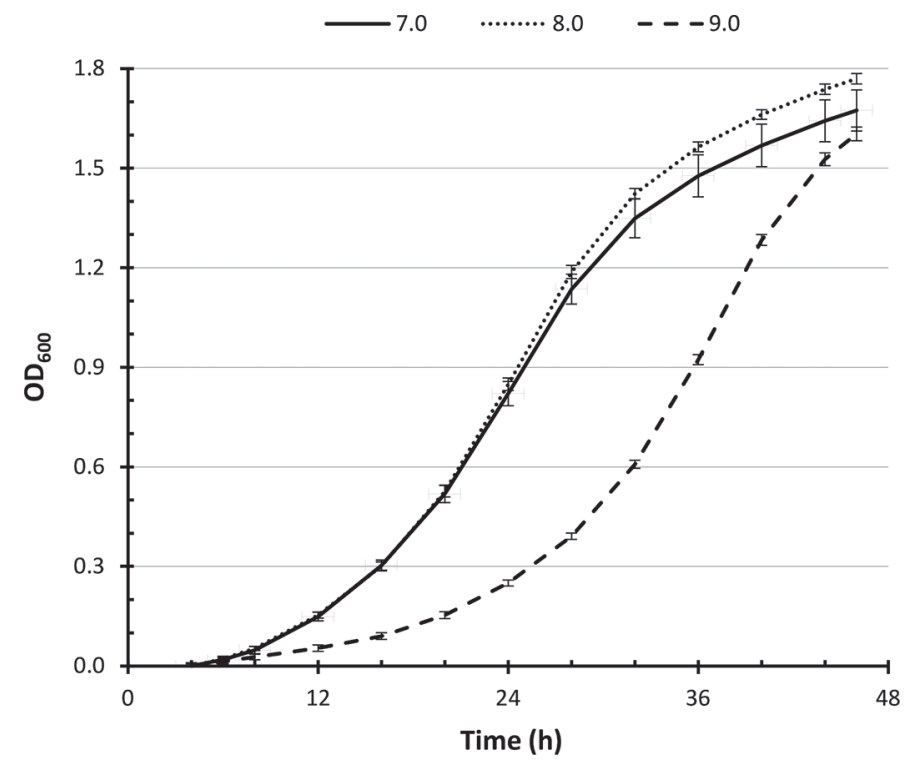

Figure 3. Growth of Paucilactobacillus wasatchensis at $25^{\circ} \mathrm{C}$ in de Man, Rogosa, and Sharpe (MRS)-ribose broth at $\mathrm{pH} 7.0,8.0$, and 9.0 in 48 -well plates with optical density measured at $600 \mathrm{~nm}\left(\mathrm{OD}_{600}\right)$, error bars $=\mathrm{SE}, \mathrm{n}=3$. 
Acidifying the MRS-R broth to make it more similar to cheese ( $\mathrm{pH} 5.2$ to 5.5) slows down the growth rate of Plb. wasatchensis (Figure 2), but the adaption made to cope with this acid stress apparently increases the ability of cells to deal with salt-induced stresses. The production of $\mathrm{pH}$-stress proteins would provide cross protection against other stresses, which could explain increased growth being observed at cheese $\mathrm{pH}$ conditions when salt was added compared with growth at neutral $\mathrm{pH}$.

In cheese, the salt-in-moisture $(\mathbf{S} / \mathbf{M})$ concentration varies considerably between blocks of cheese with standard deviations for salt content often being 0.15 percentage units. That is, even with a cheesemaking process with a target salt content of $1.7 \%$, only $68 \%$ of the cheese blocks would be expected to be in the salt range of $1.55 \%$ to $1.95 \%$ salt. Assuming a normal distribution, $13 \%$ of the cheese blocks would have salt contents between $1.40 \%$ and $1.55 \%$ and $2 \%$ would only have from $1.25 \%$ to $1.40 \%$ salt. If the target moisture of the cheese was $38 \%$, then this corresponds to cheeses with S/M levels of about $4.5 \%$ (target cheese), $3.9 \%$, and $2.6 \%$. Given that less whey is expelled when the salt content is low, the cheeses at the bottom end of the salt range would be even lower in $\mathrm{S} / \mathrm{M}$ concentration.

When $\mathrm{S} / \mathrm{M}$ levels of $3.5,4.5$, and $5.5 \%$ salt were tested as representing cheeses that were low, medium, and high in salt, respectively, it was clear that cheeses that are low in salt will promote more growth of NSLAB such as Plb. wasatchensis (Figure 4). Adding 3.5\% salt in MRS-R broth at $\mathrm{pH} 5.2$ resulted in little suppression of growth, with the OD reaching 1.2 after $46 \mathrm{~h}$ at $25^{\circ} \mathrm{C}$ compared with an OD of 1.5 for the control. With $4.5 \%$ salt, growth of Plb. wasatchensis was further repressed such that OD reached 0.9 and with $5.5 \%$ salt the OD after $46 \mathrm{~h}$ was only 0.5 . Increasing the $\mathrm{pH}$ to 5.5 reduced the amount of acid stress and the growth rate of Plb. wasatchensis was slightly higher (Table 3 ). At higher salt levels, growth was further retarded, but even at a $6.0 \%$ salt concentration, complete inhibition of Plb. wasatchensis did not occur (Figure 5). Thus, although having lower salt levels in cheese is a risk factor for growth of Plb. wasatchensis and consequent potential unwanted gas production with formation of slits and cracks in the cheese, having high levels of salt will not prevent Plb. wasatchensis from growing during extended storage of Cheddar cheese.

\section{Carbohydrate Utilization}

As shown in previous studies (Ortakci et al., 2015a) the most rapid growth of Plb. wasatchensis occurs when ribose is available as an energy source. This was appar-

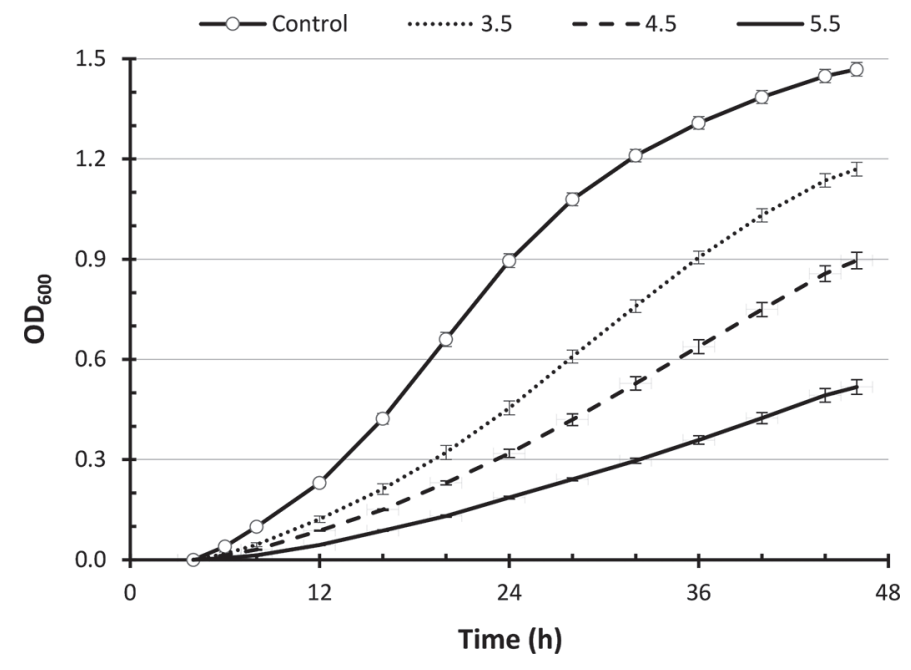

Figure 4. Inhibition of growth of Paucilactobacillus wasatchensis at salt levels typical of Cheddar cheese $(3.5,4.5$, and $5.5 \%$ salt-inmoisture) at $25^{\circ} \mathrm{C}$ in de Man, Rogosa, and Sharpe (MRS)-ribose broth at $\mathrm{pH} 5.2$, in 48-well plates with optical density measured at $600 \mathrm{~nm}$ $\left(\mathrm{OD}_{600}\right)$, error bars $=\mathrm{SE}, \mathrm{n}=3$.

ent when Plb. wasatchensis was grown in CR-MRS adjusted to cheese-like conditions ( $\mathrm{pH} 5.2$ and $4.0 \%$ salt) with ribose, galactose, or lactose as the carbohydrate (Figure 6). With ribose, $\mu_{\max }$ was $0.087 \mathrm{OD} / \mathrm{h}$ and the OD reached 1.2 in $46 \mathrm{~h}$. In comparison, growth with galactose was slower $\left(\mu_{\max }=0.038 \mathrm{OD} / \mathrm{h}\right)$ and after 46 $\mathrm{h}$ only reached an OD of 0.06 . This slower growth has been attributed to the need of the cells to re-oxidize $\mathrm{NADH}$ formed when galactose is converted to a 5-carbon sugar phosphate via the Leloir pathway so it can be fermented for the production of ATP in the pentose phosphate pathway (Ortakci et al., 2015a).

When lactose was the only carbohydrate available its growth rate was similar to that with galactose (Figure 6) but growth of Plb. wasatchensis stopped when the OD reached 0.3 . This implies that the cells ran out of energy sources after $24 \mathrm{~h}$. Similar behavior had been previously observed (Ortakci et al., 2015a) when Plb.

Table 3. Maximum specific growth rate $\left(\mu_{\max }\right)$ for growth of Paucilactobacillus wasatchensis at $25^{\circ} \mathrm{C}$ in de Man, Rogosa, and Sharpe (MRS) broth containing $1.5 \%$ ribose at $\mathrm{pH} 5.2$ and 5.5 based on salt concentration ${ }^{1}$

\begin{tabular}{lcc}
\hline & \multicolumn{2}{c}{$\mu_{\max }\left(\mathrm{OD}_{600} / \mathrm{h}\right)$} \\
\cline { 2 - 3 } Salt concentration $(\%)$ & $\mathrm{pH} 5.2$ & $\mathrm{pH} 5.5$ \\
\hline 0 & 0.119 & 0.174 \\
3.0 & 0.077 & 0.101 \\
4.5 & 0.056 & 0.071 \\
5.5 & 0.034 & 0.040 \\
\hline
\end{tabular}

${ }^{1} \mathrm{OD}_{600}=$ optical density measured at $600 \mathrm{~nm}$. 


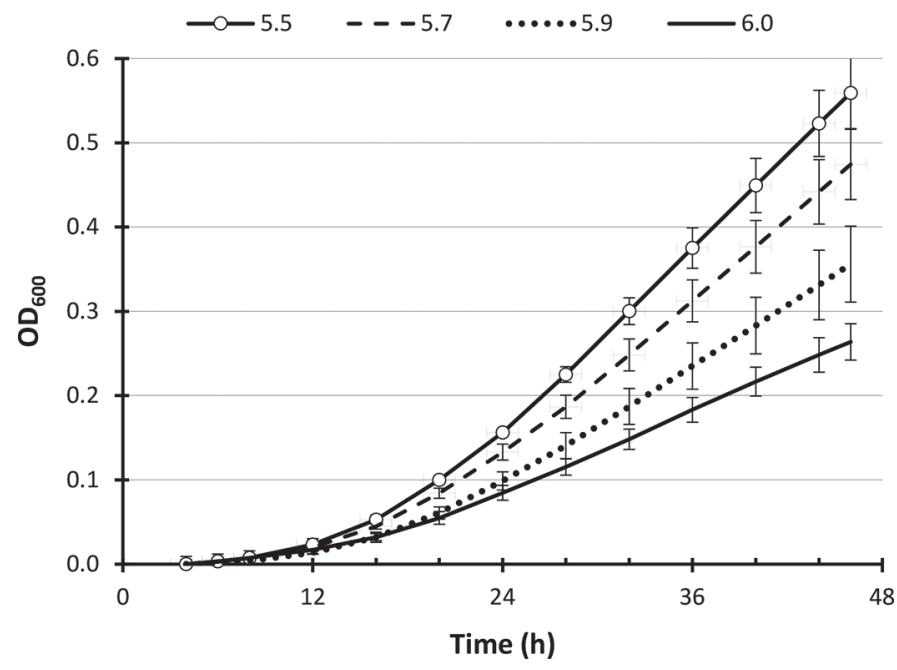

Figure 5. Growth of Paucilactobacillus wasatchensis at high salt levels from $5.5 \%$ to $6.0 \%$ at $25^{\circ} \mathrm{C}$ in de Man, Rogosa, and Sharpe (MRS)-ribose broth at $\mathrm{pH} 5.2$, in 48-well plates with optical density measured at $600 \mathrm{~nm}\left(\mathrm{OD}_{600}\right)$, error bars $=\mathrm{SE}, \mathrm{n}=3$.

wasatchensis was grown in different concentrations of ribose or galactose. When grown on CR-MRS with 0.1, 0.5 or $1.0 \%$ ribose, the growth rates were all the same and the difference was that exponential growth phase finished earlier at the lower ribose concentrations. This suggests that Plb. wasatchensis cells cannot use more than $0.1 \%$ ribose (more likely less than that) at a time so higher ribose concentrations just support growth for a longer time. This limitation of Plb. wasatchensis to

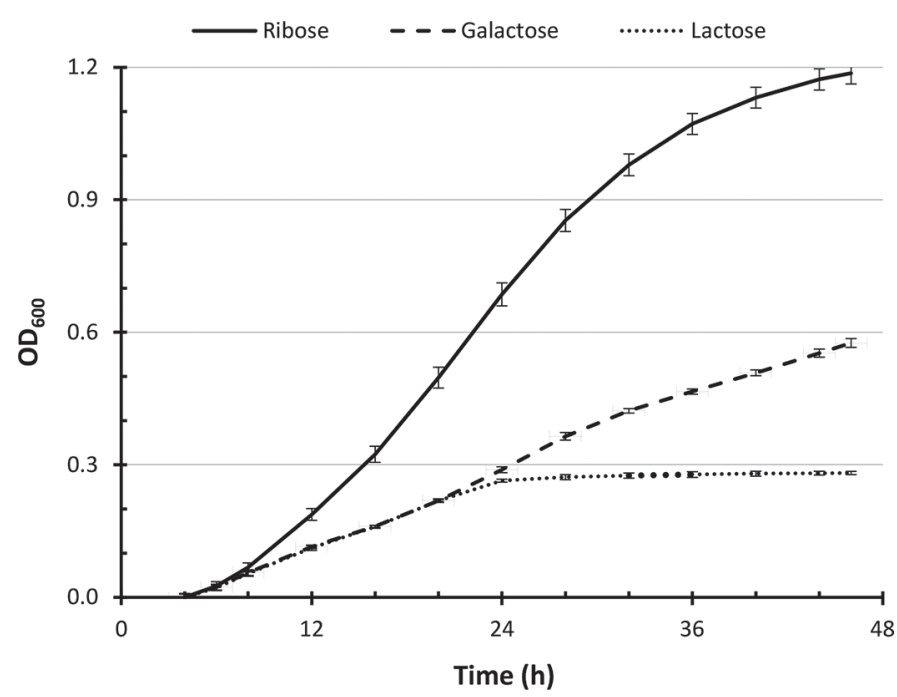

Figure 6. Growth of Paucilactobacillus wasatchensis at $25^{\circ} \mathrm{C}$ in carbohydrate-restricted de Man, Rogosa, and Sharpe (MRS) broth ( $\mathrm{pH} 5.2,4.0 \%$ salt) containing $1.5 \%$ ribose, galactose, or lactose in 48-well plates with optical density measured at $600 \mathrm{~nm}\left(\mathrm{OD}_{600}\right)$, error bars $=\mathrm{SE}, \mathrm{n}=3$. grow rapidly is evident when grown on MRS-R agar because other NSLAB form large colonies $(\sim 2 \mathrm{~mm})$ within $48 \mathrm{~h}$, whereas colonies of Plb. wasatchensis are barely visible at $24 \mathrm{~h}$ and require an additional 2 to $3 \mathrm{~d}$ of incubation to form countable colonies.

Growth of Plb. wasatchensis on CR-MRS containing only glucose (Figure 7) was similar for growth on lactose. It had a similar rate of growth $\left(\mu_{\max }=0.033\right.$ $\mathrm{OD} / \mathrm{h}$ ) and also stopped growing after $24 \mathrm{~h}$ when the OD reached $\sim 0.3$. Why less growth would occur on glucose compared with galactose was unexpected and followed the same pattern as growth on lactose (Figure 6). Utilization of galactose for energy or cell wall production was assumed to proceed with the initial conversion of galactose to 6-P-glucose. Why this should be limited when glucose is available (including through hydrolysis of lactose) is unclear. In contrast, growth of Plb. wasatchensis with fructose as the carbohydrate source (Figure 7) continued through the $46 \mathrm{~h}$ of incubation but slowed down after $24 \mathrm{~h}$ and only reached an OD of 0.45 .

Another sugar that will support growth of Plb. wasatchensis is NAG, which along with NAM and associated peptides, are components of the bacterial cell wall. These 2 sugars are $\beta$-linked in an alternating pattern to form the mesh-like polymeric structure of peptidoglycan. When Plb. wasatchensis was grown in $1.5 \%$ NAG added to CR-MRS, its growth pattern was similar to that of fructose with $\mu_{\max }$ of $0.033 \mathrm{OD} / \mathrm{h}$ and growth slowing down after $24 \mathrm{~h}$ but continuing through

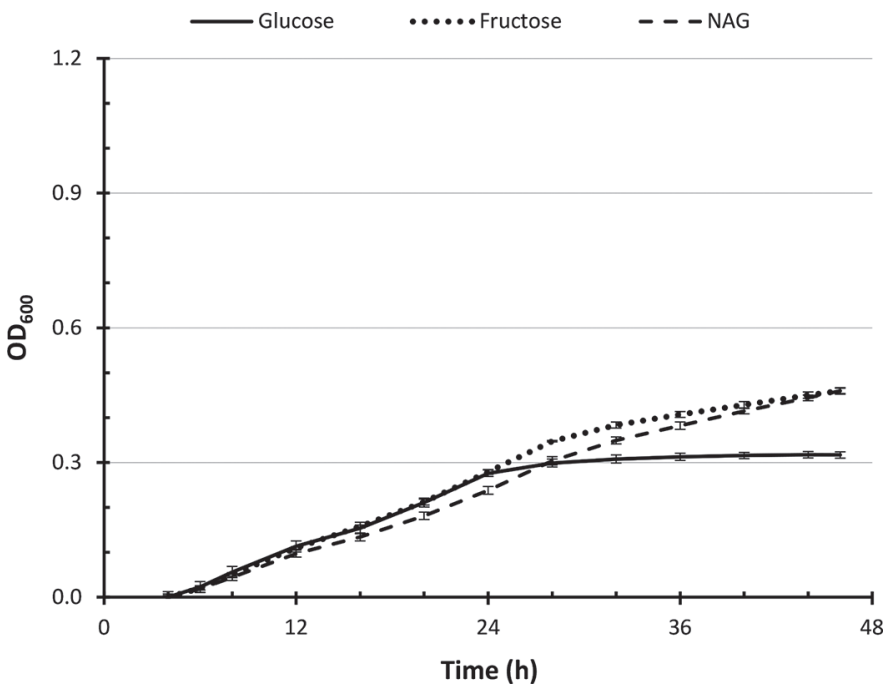

Figure 7. Growth of Paucilactobacillus wasatchensis at $25^{\circ} \mathrm{C}$ in carbohydrate-restricted de Man, Rogosa, and Sharpe (MRS) broth (pH 5.2, $4.0 \%$ salt) containing $1.5 \%$ glucose, fructose, or $N$-acetylglucosamine (NAG) in 48-well plates with optical density measured at $600 \mathrm{~nm}$ $\left(\mathrm{OD}_{600}\right)$, error bars $=\mathrm{SE}, \mathrm{n}=3$. 
$46 \mathrm{~h}$ (Figure 7). No growth of Plb. wasatchensis was observed when NAM was the only sugar.

In a cheese environment, lysis of starter culture cells after salting of the curd (and during pressing and storage of the cheese) would provide Plb. wasatchensis with at least 2 energy sources: ribose and NAG. It may be that as with other bacteria that have evolved to grow in nutrient fluctuating environments such as agricultural silage or even the human oral cavity (Moye et al., 2014), Plb. wasatchensis uses amino-sugars such as NAG for its own growth and it may also act to repress its own catabolic processes (Dobrogosz, 1968). Further studies are needed to determine if NAM could be used to support growth when ribose is also present to supply energy needs and then NAM and NAG could be used to support cell wall growth and cell division in the same way that galactose appears to do when ribose is also available (Ortakci et al., 2015a).

During Cheddar cheese manufacture, the starter culture lactococci reaches up to $10^{8}$ to $10^{10}$ cells/g in the cheese before salting (Visser, 1977; Jordan and Cogan, 1993; Fenelon et al., 2000; McMahon et al., 2014). After salting, the number of starter culture cells in the cheese can decrease by a log within a few days. Based on the bacterial cells weighing about $6.4 \times 10^{-13} \mathrm{~g}$ (Milo and Phillips, 2019) and consisting of $80 \%$ moisture, and RNA being $20 \%$ of the dry mass of bacterial cells, the amount of RNA released into the cheese serum if there were initially $10^{10}$ cells $/ \mathrm{g}$ would be about $0.23 \mathrm{mg} / \mathrm{g}$ of cheese. In a cheese with $37 \%$ moisture this would provide a ribose concentration to support NSLAB growth of about $0.25 \mathrm{mg} / \mathrm{mL}(0.025 \%)$. Although this is much lower than the levels in MRS-R broth, given the longer time involved ( $60 \mathrm{~d}$ compared with $48 \mathrm{~h}$ ) it would still support growth of Plb. wasatchensis and other NSLAB.

Cheese has a relative abundance of amino acids from the hydrolysis of the casein proteins by residual coagulant along with the starter culture and NSLAB proteases and peptidases. In addition to ribose, NAG and other cell components from starter culture lysis would also be available. The number of starter culture cells present in the cheese curd before salting can then contribute to NSLAB growth. In previous studies (McMahon et al., 2014), we have typically observed lactococcal starter culture numbers before salting of $10^{9} \mathrm{cfu} / \mathrm{g}$ with a drop to $10^{8} \mathrm{cfu} / \mathrm{g}$ after pressing. For such cheese, the ribose level upon autolysis of starter cultures would only be $0.0025 \%$ and less growth of NSLAB would be supported. Adding an adjunct starter culture such as Lactobacillus helveticus that also undergoes lysis during storage would also add additional cellular components to support growth of NSLAB.

Ribose, along with other scavenged biocellular nutrients such as NAG as well as any residual galactose and lactose, could then support slow but ongoing growth of Plb. wasatchensis in the cheese. When the number of Plb. wasatchensis cells reaches a high level and 6-carbon sugars are used for energy, enough carbon dioxide can be produced to cause slits and cracks in the cheese.

\section{Organic Acids}

The effect of adding organic acids to MRS-R medium on growth of Plb. wasatchensis varied depending on the type and amount of acid added (Table 4). The level of acid added had been selected based upon our observation of the ranges at which they naturally occur in cheese (McMahon et al., 2014). In general, more inhibition of growth was observed when the medium was initially adjusted to $\mathrm{pH} 5.1$. This can be considered as a reduction of growth of Plb. wasatchensis as $\mathrm{pH}$ falls below $\mathrm{pH} 5$ and was most evident with organic acids added at higher molarity levels. In this part of our study, when Plb. wasatchensis WDC04 was grown in 48-well plates using MRS-R broth at $\mathrm{pH} 7.0$ or 5.1, the OD increased about 0.6 units over $40 \mathrm{~h}$ (data not shown). The largest effect was when lactic acid with growth dropping by about $70 \%$ at $\mathrm{pH} 7$ and virtually

Table 4. Extent of suppression of growth of Paucilactobacillus wasatchensis at $25^{\circ} \mathrm{C}$ in de Man, Rogosa, and Sharpe (MRS) broth containing $1.5 \%$ ribose in presence of organic acids at the low, middle, and high levels observed in cheese (see Table 2)

\begin{tabular}{|c|c|c|c|c|c|c|}
\hline \multirow[b]{3}{*}{ Acid (\%) } & \multicolumn{6}{|c|}{ Inhibition } \\
\hline & \multicolumn{3}{|c|}{ pH 7.0} & \multicolumn{3}{|c|}{ pH 5.1} \\
\hline & Low & Mid & High & Low & Mid & High \\
\hline Lactic & 70 & 74 & 66 & 93 & 91 & 99 \\
\hline Formic & 10 & 68 & 86 & 34 & 75 & 91 \\
\hline Propionic & 14 & -31 & -17 & -11 & 8 & 76 \\
\hline Citric & 60 & 69 & 21 & 90 & 88 & 69 \\
\hline Acetic & -12 & -22 & -1 & -7 & -2 & 26 \\
\hline
\end{tabular}


no growth at pH 5.1 medium when $560 \mathrm{~m} M$ lactic acid was added. Although these are the levels of lactic acid in cheese, the $\mathrm{pH}$ is buffered by the proteins and phosphate and the cheese remains above $\mathrm{pH} 5.1$ (Ortakci et al., 2015b).

Adding $26 \mathrm{~m} M$ formic acid slightly inhibited $P l b$. wasatchensis growth (10 and $34 \%$ at $\mathrm{pH} 7$ and 5.1, respectively) and increased as formic acid addition increased to $100 \mathrm{~m} M$ reached about $86 \%$ suppression at $\mathrm{pH} 7$ and $91 \%$ at $\mathrm{pH}$ 5.1. Adding propionic acid appears to be stimulatory to growth of Plb. wasatchensis and showed negative inhibition at $\mathrm{pH} 7$ with this effect being more apparent when 38 and $70 \mathrm{mM}$ propionic acid was added. At $\mathrm{pH} 5.1$, adding propionic acid at 70 $\mathrm{m} M$ apparently caused sufficient drop in $\mathrm{pH}$ to result in $76 \%$ inhibition of Plb. wasatchensis growth. In contrast, 12 to $15 \mathrm{~m} M$ addition of citric acid caused inhibition at both $\mathrm{pH} 7$ and $\mathrm{pH}$ 5.1, suggesting its calcium chelating properties influenced growth. This is probably not an issue in cheese as there is an abundance of free calcium ions even when this amount of citrate is present. Adding acetic acid had a similar effect to adding propionic acid and either had a stimulating effect on growth at $\mathrm{pH}$ 7. A slight inhibition occurred with the highest acetic acid addition $(17 \mathrm{mM})$ into the $\mathrm{pH} 5.1$ medium.

\section{CONCLUSIONS}

When milk was processed through a HTST pasteurizer, no survival of Paucilactobacillus wasatchensis WDC04 was detected with an 8-log reduction in cfu/ $\mathrm{mL}$ occurring using pasteurization $\left(72^{\circ} \mathrm{C}\right.$ for $\left.15 \mathrm{~s}\right)$ or sub-pasteurization heating at $\left(69^{\circ} \mathrm{C}\right.$ for $\left.15 \mathrm{~s}\right)$. Lowering $\mathrm{pH}$ to 5.1 and increasing salt comparable to $6 \% \mathrm{~S} / \mathrm{M}$ slows but does not stop growth of Plb. wasatchensis WDC04, so, if present as part of the NSLAB population in cheese, it can still grow. In addition to ribose and galactose, Plb. wasatchensis WDC04 can also utilize glucose, fructose, lactose, and NAG to support growth. Growth of Plb. wasatchensis WDC04 was fastest with ribose, whereas growth rates with glucose, fructose, lactose, and NAG were similar to that with galactose. Both residual galactose and lactose in cheese can help support growth and could lead to unwanted gas production. Unwanted gas production in cheese is likely to occur when Plb. wasatchensis reaches high numbers and there is still residual galactose in the cheese. This and previous studies indicate that the risk factors for having slits and cracks in Cheddar cheese are (1) high initial NSLAB numbers that include $P l b$. wasatchensis or similar OHF lactobacilli, (2) high starter culture numbers at the end of cheesemaking followed by lysis of cells, which makes ribose and NAG available to sup- port growth of Plb. wasatchensis, (3) low salt levels in the cheese, (4) high cheese $\mathrm{pH},(5)$ residual galactose in the cheese, such as from use of Strep. thermophilus as part of the starter culture, and (6) elevated storage temperatures to accelerate cheese aging.

\section{ACKNOWLEDGMENTS}

Authors Bowen and Green thank BUILD Dairy program of the Western Dairy Center for support of their research studies and financial support from Dairy West and regional dairy processing companies. This research was also supported by the Utah Agricultural Experiment Station, Utah State University (Logan, UT), and approved as journal paper number 9299. We also thank David Irish and David Campbell (Aggie Creamery, Utah State University) for assistance in using the HTST pasteurizer. The authors have no conflicts of interest.

\section{REFERENCES}

Culumber, M., D. J. McMahon, F. Ortakci, L. Montierth, B. Villalba, J. Broadbent, and C. J. Oberg. 2017. Geographical distribution and strain diversity of Lactobacillus wasatchensis isolated from cheese with unwanted gas formation. J. Dairy Sci. 100:8764-8767. https://doi.org/10.3168/jds.2017-13375.

de Man, J. C., M. Rogosa, and M. E. Sharpe. 1960. A medium for the cultivation of lactobacilli. J. Appl. Bacteriol. 23:130-135. https:// doi.org/10.1111/j.1365-2672.1960.tb00188.x.

Dobrogosz, W. J. 1968. Effect of amino sugars on catabolite repression in Escherichia coli. J. Bacteriol. 95:578-584. https://doi.org/ 10.1128/JB.95.2.578-584.1968.

Fenelon, M. A., P. O'Connor, and T. P. Guinee. 2000. The effect of fat content on the microbiology and proteolysis in Cheddar cheese. J. Dairy Sci. 83:2173-2183. https://doi.org/10.3168/jds.S0022 -0302(00)75100-9.

Jordan, K. N., and T. M. Cogan. 1993. Identification and growth of non-starter lactic acid bacteria in Irish Cheddar cheese. Ir. J. Agric. Food Res. 32:47-55.

McMahon, D. J., C. J. Oberg, M. A. Drake, N. Farkye, L. V. Moyes, M. R. Arnold, B. Ganesan, J. Steele, and J. R. Broadbent. 2014. Effect of sodium, potassium, magnesium, and calcium salt cations on $\mathrm{pH}$, proteolysis, organic acids, and microbial populations during storage of full fat Cheddar cheese. J. Dairy Sci. 97:4780-4798. https://doi.org/10.3168/jds.2014-8071.

Milo, R., and R. Phillips. 2019. Cell biology by the numbers: How big is an E. coli cell and what is its mass? Accessed Dec. 16, 2019. http://book.bionumbers.org/how-big-is-an-e-coli-cell-and-what-is -its-mass.

Moye, Z. D., R. A. Burne, and L. Zeng. 2014. Uptake and metabolism of $\mathrm{N}$-acetylglucosamine and glucosamine by Streptococcus mutans. Appl. Environ. Microbiol. 80:5053-5067. https://doi.org/10.1128/ AEM.00820-14.

Oberg, C. J., T. S. Oberg, M. C. Culumber, F. Ortakci, J. R. Broadbent, and D. J. McMahon. 2016. Lactobacillus wasatchensis sp. nov., a non-starter lactic acid bacteria isolated from aged Cheddar cheese. Int. J. Syst. Evol. Microbiol. 66:158-164. https://doi.org/ 10.1099/ijsem.0.000689.

Ortakci, F., J. R. Broadbent, C. J. Oberg, and D. J. McMahon. 2015a. Growth and gas production of a novel obligatory heterofermentative Cheddar cheese nonstarter lactobacilli species on ribose and galactose. J. Dairy Sci. 98:3645-3654. https://doi.org/10.3168/jds .2014-9293. 
Ortakci, F., J. R. Broadbent, C. J. Oberg, and D. J. McMahon. 2015b. Late blowing of Cheddar cheese induced by accelerated ripening and ribose and galactose supplementation in presence of a novel obligatory heterofermentative nonstarter Lactobacillus wasatchensis. J. Dairy Sci. 98:7460-7472. https://doi.org/10.3168/jds.2015 -9468 .

Ortakci, F., J. R. Broadbent, C. J. Oberg, and D. J. McMahon. 2015c. Growth and gas formation by Lactobacillus wasatchensis, a novel obligatory heterofermentative nonstarter lactic acid bacterium, in Cheddar-style cheese made using a Streptococcus thermophilus starter. J. Dairy Sci. 98:7473-7482. https://doi.org/10.3168/jds .2015-9556

Visser, F. M. W. 1977. Contribution of enzymes from rennet, starter bacteria and milk to proteolysis and flavour development in Gouda cheese. 1. Description of cheese and aseptic cheesemaking. Neth. Milk Dairy J. 31:120-133.

Zeibich, L., M. Staege, O. Schmidt, and H. L. Drake. 2019. Amino acids and ribose: Drivers of protein and RNA fermentation by ingested bacteria of a primitive gut ecosystem. Appl. Environ. Microbiol. 85:e01297-19. https://doi.org/10.1128/AEM.01297-19.

Zheng, J., S. Wittouck, E. Salvetti, C. M. A. P. Franz, H. M. B. Harris, P. Mattarelli, P. W. O'Toole, B. Pot, P. Vandamme, J. Walter, K. Watanabe, S. Wuyts, G. E. Felis, M. G. Gänzle, and S. Lebeer. 2020. A taxonomic note on the genus Lactobacillus: Description of 23 novel genera, emended description of the genus Lactobacillus Beijerinck 1901, and union of Lactobacillaceae and Leuconostocaceae. Int. J. Syst. Evol. Microbiol. 70:2782-2858. https://doi.org/ 10.1099/ijsem.0.004107.

\section{ORCIDS}

Donald J. McMahon (ㄴ) https://orcid.org/0000-0002-7923-8542

Isaac B. Bowen ( https://orcid.org/0000-0002-7218-1627

Craig J. Oberg (๑) https://orcid.org/0000-0001-6033-7033 